\title{
Downsizing the Labor Force by Low and High Profit Firms
}

\section{- An Experimental Analysis}

\author{
Werner Güth (Corresponding author) \\ Max Planck Institute of Economics \\ 10 Kahlaische Street, D-07745 Jena, Germany \\ E-mail: gueth@econ.mpg.de
}

Christian Paul

Institute of Economic Theory and Statistics (ETS)

Karlsruhe Institute of Technology (KIT), Germany

E-mail:paul-christian@gmx.de

Received: April 5, 2011 Accepted: May 20, 2011 doi:10.5539/jms.v1n1p2

The authors gratefully acknowledge financial support from the German Research Foundation (DFG), research program: Flexibility in Heterogenous Labor Markets. Furthermore, we have benefited from helpful comments by Marion Ott, Karl-Martin Ehrhart, and Ralf Löschel.

\begin{abstract}
We theoretically and experimentally employ a principal-agent setting to capture the effects of downsizing the labor force. One of the two main treatments features a large increase of the principal's profit and another one a rather low increase. Our main experimental findings are that downsizing often is avoided and that its frequency does not depend on its profitability. There is evidence that agents spend more effort when downsizing is more profitable what might explain that downsizing frequencies hardly depend on the profitability.
\end{abstract}

Keywords: Downsizing, Experimental economics, Principal-agent model, Labor economics

\section{Introduction}

Downsizing is often understood as laying off a large group of workers and has become a synonym for, allegedly unfair, firing decisions in popular (science) literature. More broadly, downsizing could refer to all situations where a subgroup of interacting parties within an organization would have better success or survival prospects than the whole group. Dramatic examples of lifeboats with too little water or food for all can be found in novels and are hopefully more often fictional than factual. One reaction to such challenges could be volunteers offering to be excluded. But such hero volunteers are probably a rare species. What one realistically has to expect are attempts of some parties to exclude others against their will. This does not only invoke material aspects but also raises moral and emotional concerns not only of those who suffer, e.g., by being excluded, but also of those who exclude others.

There is no hope to capture such dramatic circumstances in the lab without violating ethical constraints. But downsizing is not restricted to such dramatic events. People may exclude others from social activities because interaction in smaller group is more fun or more efficient. When going by car to attend an event it may be, for instance, more enjoyable to go with just one or two other friends than to have one's car packed to the limit. This illustrates that downsizing may invoke minor or major effects for those who are dismissed as well as for those who stay on. Although, of course, the exact size of these effects will matter, the qualitative effects are interesting as well. This, in our view, justifies an experimental approach to explore downsizing; not to substitute field research but to complement it.

One can hope to capture crucial aspects of firms' downsizing decisions by employing rather abstract scenarios like ultimatum games, e.g., with one proposer and several responders of whom some can be excluded (Fischer, 
Güth, and Köhler (2009)). But then questions like "Why can the proposer and some responders exclude other responders?" or "Why can the remaining players share more, and how is that related to what all would receive?" naturally arise. These are less troublesome when considering situations for which downsizing is typical, namely a firm which tries to reduce its labor force, although it is prospering.

This suggests a principal-agent setting and that the initiative for downsizing rests on the owners, respectively their delegates, e.g., CEOs. What can be gained by downsizing is implied by the economic, technological, and legal environment. A smaller labor force may avoid bankruptcy, resembling the example of a lifeboat whose supplies do not suffice for all. Investigating such situations in which either all suffer or some survive may yield important insights. But here we focus on situations in which downsizing is not a matter of immediate necessity but one of profitability.

Such, allegedly unfair, downsizing announcements regularly alert the public all over the world (New York Times (2008)). In Germany, e.g., in January 2008, the mobile phone producer Nokia announced to shut down a factory in Bochum, Germany, and lay off 4,300 full-time employees and temporary workers, although internal accounting showed a profit of 134Million Euros (Note 1). In February 2008, the household products company Henkel and the automobile manufacturer BMW announced layoffs of 3,000 and 8,100 workers, respectively, although their profits had increased (to about 1 billion Euros and more than 3.75 billion Euros, respectively). These firms justified downsizing by future risks due to the Global Economy (Henkel) or simply by higher rentability aspirations (BMW, Note 2).

We study downsizing experimentally, although the external validity of such experiments for life-altering payoffs might be problematic, especially when real layoffs induce dramatic consequences that cannot be perfectly reproduced in the lab. But, as already mentioned, downsizing does not always induce life-altering consequences, and we are confident that behavioral aspects of layoffs can be captured at least qualitatively. More specifically, we experimentally examine downsizing and its behavioral effects in a principal-agent setting where workers choose effort (Note 3). We use minimum wages as a labor market rigidity to render downsizing profitable. In a treatment in which a principal's profit gain from downsizing his labor force is positive, but rather small, we expect less layoffs than in another treatment in which this gain is rather large. Other research questions are: do game theoretic benchmark solutions correctly predict the actual behavior? Are there probation period effects? Will there be differences between anticipated and unanticipated downsizing and, if so, will they question the profitability of downsizing?

One major finding is that downsizing does not seem to depend on theoretically predicted nor on actually earned profits. This might be due to another finding, namely that workers invest more effort when firing incentives are high, especially when anticipating that employers are allowed to fire them later on. Employer participants who downsize their labor force are those who previously earned relatively less. Compared to the benchmark predictions piece rate offers are surprisingly low.

The firm model to be analyzed theoretically and implemented experimentally, is introduced in Section 2 together with its solution. Section 3 describes the experimental protocol, Section 4 discusses the hypotheses. After analyzing the data in Section 5, Section 6 concludes.

\section{The principal-agent model}

\subsection{Model description}

Principal $P$ currently employs both, a highly productive agent (agent $h)$ with costs $C_{h}\left(e_{h}\right)$ of effort $e_{h}$ and a less productive one $(l)$ with costs $C_{l}\left(e_{l}\right)$. Both produce the same kind of output. The highly productive agent (Note 4$)$ has lower costs of effort, i.e., $C_{h}(e)$ is smaller than $C_{l}(e)$ for all positive effort levels $e$. More specifically, we rely on quadratic effort cost functions $C_{h}\left(e_{h}\right)=k / 2 \bullet\left(e_{h}\right)^{2}$ and $C_{l}\left(e_{l}\right)=d / 2 \bullet\left(e_{l}\right)^{2}$ with $0<k<d$. Each unit of effort results in one unit of output. The principal perfectly observes the agents' types and the amount of output produced (Note 5).

To render downsizing profitable, we assume the labor market rigidity of minimum wages and impose nondiscriminatory contract offers for all workers (Note 6). Workers' outside options like unemployment benefits are denoted by $U$ and are smaller than the minimum fixed wage, $M$. On the sales market the product price $p$ is positive and constant. A linear employment contract specifies the fixed wage $F$ and the same piece rate, $r$, for all workers. The principal's profit, $\Pi$, is

$$
\text { (1) } \pi=(p-r)\left(\epsilon_{5}+\epsilon_{2}\right)-2 \cdot F
$$


Employees' earnings, $\omega$, are

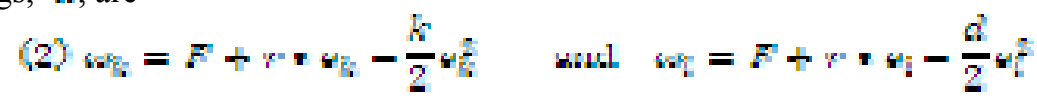

for the highly productive agent $h$ and the less productive agent $l$, respectively.

The game is played finitely often. In the first $x$ stages, the principal employs both agents; downsizing is impossible in these stages. Output is produced, learned by all parties, and sold. Profits, efforts, and earnings are assumed to be common knowledge. After the first $x$ stages, the principal can lay off part of her labor force, i.e., downsize. More specifically, the less productive agent may be dismissed while the more productive agent remains in the firm. Although game theoretically it does not matter whether players know ex ante that downsizing is possible after $x$ stages, behaviorally this might be very relevant. In the last $y$ stages, output is produced by the agents still employed. We now solve this downsizing game starting with the agents' effort choices.

\subsection{Effort decisions}

From (2) one derives the agents' optimal effort choices as $e_{h}{ }^{*}=r / k$ and $e_{l}{ }^{*}=r / d$ for the highly and less productive agent, respectively. Agents obviously want to be employed since $M>U$ (Note 7). Inserting the optimal efforts into the principal's profit function yields

$$
\text { (3) } \Pi=(q-r)\left(\frac{r}{i}+\frac{r}{d}\right)-2 \cdot F
$$

\subsection{Contracts before downsizing}

Denoting the contract offer before the downsizing decision by $\left(F_{B}, r_{B}\right)$, the principal maximizes (3) subject to the minimum wage constraint (MWC1) $F_{B} \geq M$, which is obviously binding in optimum.

The optimal piece rate and the resulting effort levels are $r^{*}=p / 2, e_{h}{ }^{*}=p /(2 k)$, and $e_{l}{ }^{*}=p /(2 d)$ (Note 8). Both workers earn more than the outside option with the less productive worker earning less than the highly productive one:

$$
v \propto \omega_{i}=M+\frac{p^{2}}{g d} \times \omega_{S}=H+\frac{p^{2}}{3 k} \text { dus to } k \propto \alpha
$$

The principal's profit,

$$
I^{\prime \prime}=\frac{d+k}{4 w^{2}} p^{2}-2 \cdot M
$$

is positive for

$$
H \leq B_{1}:=\frac{d+k}{8 d k} p^{2}
$$

\subsection{Contracts after downsizing}

After laying off the less productive worker, the principal's contract offer, denoted by $\left(F_{A}, r_{A}\right)$, maximizes

$$
(p-n) \frac{n}{k}-F_{A}
$$

subject to the minimum wage constraint (MWC2) $F_{A} \geq M$. The optimal piece rate and effort level are $r^{* *}=p / 2$ and $e_{h}^{* *}=p /(2 k)$. Only the highly productive worker earns more than the outside option:

$$
\omega_{i}^{*}=U \omega_{S}^{*}=M+\frac{p^{2}}{8 k}
$$

The principal's profit,

$$
\Pi^{4}=\frac{p^{2}}{4 k}-M
$$

is positive for $M \leq B_{2}$ with $B_{2}:=p^{2} /(4 k)$. 


\subsection{Downsizing}

Downsizing is profitable for the principal if

$$
\pi=\pi * 0 \text { or }-\frac{p^{2}}{42}+4=0
$$

This holds true for $\mathrm{d} \rightarrow \infty$ or, more generally, for $M>B_{3}:=p^{2} /(4 d)$. It is easy to see that $B_{3}<B_{1}<B_{2}$ always holds (Note 9). Thus, to guarantee that profits are nonnegative and downsizing is profitable, it suffices to impose $B_{3}<M<B_{1}<B_{2}$ for the minimum wage. By varying $M$ between $B_{1}$ and $B_{3}$, the downsizing profitability can be varied what we exploit when distinguishing between our two experimental treatments.

\section{Experimental design}

\subsection{Basic Design}

The experiment implements the principal-agent model. In the beginning, three participants interact: one principal (P-participant), one highly productive agent (H-participant), and one less productive agent (L-participant). Eight such triplets of participants form a session with altogether 24 participants. We performed two sessions of each treatment.

The experiment consists of $x=2$ rounds without the possibility to downsize and $y=2$ rounds afterwards. We refer to these four rounds as first phase. During the first phase, participants are not aware that a perfect stranger repetition, i.e., a repetition in which no participant meets the same participants again, of the same four rounds (second phase) will be played afterwards. They are told, however, that another experiment would follow and that they will definitively not interact with the same participants again.

In the announced downsizing, high incentive-treatment (AH) all participants know from the beginning that after the first $x=2$ rounds the principal can downsize and that two more rounds will be played thereafter. Furthermore, the principal's theoretical profit gain from downsizing is rather large.

The only difference in the announced downsizing, low incentive-treatment (AL) is that the profit increase from downsizing is rather small.

In the unannounced downsizing, high incentive-treatment (UH) participants are not told ex ante that downsizing will be possible after two rounds, i.e., they play the first two rounds without expecting the downsizing opportunity (Note 10). The theoretical profit gain is the same as in AH. The first phase of this experiment was used as a separate treatment while the data of the repetition are pooled with treatment $\mathrm{AH}$ (see Section 5).

After the first phase, participants in treatments $\mathrm{AH}$ and $\mathrm{AL}$ are told that one repetition of all four rounds of their corresponding treatment will follow (in a perfect stranger design). We denote the first phase of treatment $\mathrm{AH}$ with AH (1stphase), the second phase with AH (2ndphase), and so on. Since participants in the UH-treatment should anticipate the downsizing opportunity in the second phase, we also announced the downsizing option to them in UH (2ndphase).

\subsection{Treatment parameters}

We constantly set $d=12, k=2, U=15, p=24$, in experimental currency units (ECU). In treatments $\mathbf{A H}$ and $\mathbf{U H}$, we furthermore set $M=24$. For the sake of readability, we denote the time (before (B) or after downsizing (A)) with an index on the lower right and use indexes only if indispensable.

The optimal contracts before downsizing require $F_{B}=24$ and $r_{B}=12$ in both treatments. Optimal effort levels are $e_{h}{ }^{*}=6$ for the highly productive agent, $h$, and $e_{l}{ }^{*}=1$ for the less productive one, $l$. Payoffs are $\omega_{i}=30$ for worker $1, \omega_{\xi}=60$ for worker $h$, and $\mathbb{I}_{z}=36$ for the principal. The principal should downsize and offer the same contract to the remaining agent. Payoffs are then $\omega_{I A}=15, \omega_{\Omega A}=60$, and $\Pi_{A}=48$. Thus, downsizing increases the profit by about $33.3 \%$. The principal's absolute gain is smaller than what the less productive agent loses, and welfare defined as total payoffs decreases even though the unemployment benefit is externally paid. Efficiency forbids downsizing and suggests that agents double their effort levels to $e_{l}^{+}=p / d$ and $e_{h}^{+}=p / k$, respectively (Note $11)$.

In treatment $\mathbf{A L}$, we set $M=16$. The optimal contract before downsizing requires $F_{B}=16$ and $r_{B}=12$. Optimal efforts are unaffected. Payoffs are lower for the workers $\left(\omega_{i, z}=22\right.$ and $\left.\omega_{s, z}=52\right)$ and higher for the principal $\left(\mathbb{\Pi}_{\bar{g}}=52\right)$ due to the lower minimum wage. The principal should downsize and offer the same contract to the highly productive agent. Payoffs are then $\omega_{l, A}=15, \omega_{h, A}=52$, and $\Pi_{A}=56$. This means that principal $P$ can increase the profit by about $7.7 \%$. Again, the agent's loss more than outweighs the principal's gain and welfare 
decreases.

Note that treatments $\mathrm{AH}$ and $\mathrm{UH}$ only render downsizing more profitable than treatment AL what does not imply that the principal earns more in treatment AH and UH than in treatment AL. One, of course could have kept the principal's earning before or after downsizing constant across treatments, which are all based on the same principal-agents model, by adjusting the experimental currency unit (ECU) accordingly. But this would have controlled the profits of the principal and not at all the workers' earnings. We therefore decided against trying to control profitability of the firm across treatments.

We will refer to the results for treatments $\mathrm{AH}, \mathrm{UH}$, and $\mathrm{AL}$ as benchmark predictions from now on.

\subsection{Software, framing, miscellaneous}

All participants received a fixed fee of $F F=90 \mathrm{ECU}$ in each of the two phases of the experiment. We split this amount into two parts, $F F_{1}$ and $F F_{2}$ (45 ECU for rounds 1 and 2, $45 \mathrm{ECU}$ for rounds 3 and 4), in the first phase of the UH-treatment. The experiment was programmed and conducted with z-Tree (see Fischbacher (2007)).

Contract offers and effort choices were restricted to reasonable intervals (Note 12). Furthermore, employees were prohibited from choosing effort levels leading to negative earnings for the given contract. Principals were asked to give conjectures about the effort choices of their agents. Their contract offer in combination with these conjectures about effort choices was not allowed to imply negative expected payoffs (Note 13). These restrictions could be checked by participants with a calculator, provided by the software. Each participant could use this device up to two minutes each round to calculate all resulting payoffs from any combination of $F, r, e_{l}$, and $e_{h}$.

Nevertheless, principals' earnings could be negative when overestimating efforts. Losses, if occurring, were subtracted from cumulative earnings and the fixed fee. We informed subjects that aggregate losses had to be paid out of pocket or by administrative work (to avoid excluding participants whose aggregate payoffs approach zero as, e.g., Fehr, Klein and Schmidt (2007) do). We stressed that this was very unlikely to happen (actually, a moderate overall loss occurred only once).

The instructions refer to "employer", "employee", "fixed wage", "piece rate", and "layoffs". Although framed instructions could strengthen imported views, we explicitly wanted to analyze a phenomenon connected to labor markets (in similar labor market experiments almost no framing effects were found, e.g., Fehr et al. (2007)). Representative instructions are given in Appendix A.

Two sessions of each treatment were played. Thus we employed 48 participants per treatment and 144 participants altogether who were recruited, using the software ORSEE (Greiner (2004)). Before the experiment, participants had to answer a few control questions (at their computer terminal) to check whether they understand the instructions. All sessions were conducted at the computer laboratory of the Max Planck Institute, Jena. Participants were students. Experimental sessions lasted about 100 minutes. Average earnings were 14.55 Euros (about 8.70 Euro per hour).

\section{Hypotheses}

Due to other-regarding preferences (Note 14), P-participants in our downsizing experiment may refrain from downsizing. Since material gains from downsizing are larger in the AH-treatment, we expect downsizing in this case more often. Charness and Rabin (2002) find that efficiency seeking may dominate fairness concerns. This result supports the following

Hypothesis I: There is less downsizing in the AL-treatment than in the AH-treatment. Downsizing occurs in AH as often as in UH. Downsizing will often be avoided in all treatments.

For contract offers, other-regarding preferences like inequity aversion, altruism, or fairness (see, e.g., Rabin (1993) or Bolton and Ockenfels (2000)) might induce at least some P-participants to offer better terms than predicted. In a broader sense, our experiment could also be perceived as a trust game (see Cox (2004) or Kirstein and Bleich (2008)). Since too low piece-rates harm principal and agents, we do not expect them. In particular, contract offers significantly above the optimum could trigger reciprocity, i.e., effort levels above the benchmark predictions (Brandts and Charness (2004), Dufwenberg and Kirchsteiger (2004)).

Hypothesis II: Piece-rate offers are concentrated at or above their benchmark level. Fixed wage offers exceed the minimum fixed wage.

Anticipating the downsizing opportunity could affect the effort levels of less productive workers. In the AH-treatment, L-participants know that they can be fired and might exert more effort before the downsizing decision than in the UH-treatment. We expect probation period effects of the L-participants who might invest 
more effort before the downsizing decision than afterwards. We are also interested in how the remaining agents react to witnessing layoffs. Do they perceive the firing of other agents as an unkind action of their principal and react reciprocally - here by lowering their effort level?

Hypothesis III: a) Effort levels of the less productive workers reveal a probation period effect.

b) Effort levels of H-participants will partly decrease after witnessing the firing of L-participants.

Overall, we expect payoffs slightly above the benchmark predictions due to other-regarding preferences.

Hypothesis IV: Payoffs and welfare slightly exceed their benchmark levels.

\section{Experimental results}

In each session, 8 triplets played the game twice, i.e., two sessions supplied us with 16 triplets of average data before and after downsizing. For treatment AH, e.g., we used the averages of the two rounds before downsizing as independent observations (observations: $\mathrm{AH}\left(1_{\mathrm{B}}\right), \mathrm{AH}\left(2_{\mathrm{B}}\right), \ldots, \mathrm{AH}\left(16_{\mathrm{B}}\right)$ ). The averages of the two rounds after downsizing were used as mutually independent observations (observations: $\mathrm{AH}\left(1_{\mathrm{A}}\right), \mathrm{AH}\left(2_{\mathrm{A}}\right), \ldots, \mathrm{AH}\left(16_{\mathrm{A}}\right)$ ) that depend on observations $\mathrm{AH}\left(1_{\mathrm{B}}\right)-\mathrm{AH}\left(16_{\mathrm{B}}\right)$. Since we used a perfect stranger design, we pooled the data of the first and second phases of treatments $\mathrm{AH}$ and AL. Specifically, we pooled the data AH(1stphase) with $\mathrm{AH}(2$ ndphase) and AL(1stphase) with AL2(2ndphase), respectively (Note 15). We denote the pooled data sets by $\mathrm{AH}(32)$ and $\mathrm{AL}(32)$.

In the repetition of treatment UH, participants probably anticipated the downsizing opportunity. UH (1stphase) thus is a single treatment with 16 observations before and after downsizing (named UH (16)) to check differences to treatment $\mathrm{AH}$. The perfect stranger design and essentially the same procedures and instructions (Note 16) as in AH (2ndphase) suggest to pool the data of UH (2ndphase) with AH (32). We checked this and found it confirmed by the data before downsizing, and only violated for the piece-rate offer after downsizing (Note 17) a small lack of congruency probably due to the small number of observations in UH(2ndphase). We decided to pool the data before and after downsizing (denoted with AH (48)) and only mention the minor differences to $\mathrm{AH}(32)$ in endnotes.

All statistical tests are performed two-sided and adjusted for ties if necessary. When using a concrete significance criterion, it is always $a=.05$. Using the Wilcoxon-Mann-Whitney U-test for detecting differences in central tendency between two small samples is debatable when dealing with unequal variances or differently shaped distributions. Here, robust rank-order tests seem more appropriate (see, e.g., Feltovich (2003, 2005), Fligner and Policello (1981), Ruxton (2006), or Siegel and Castellan (1988)). Thus, we use standard non-parametric tests for small samples $(n<30)$ and for ordinal data, but calculate robust rank-order tests in addition to U-tests whenever necessary (Note 18$)$. For large samples $(n \geq 30)$, we always use parametric tests. When comparing population means, we revert to the Welch-Satterthwaite independent two-sample $t$ test without prior variance checks as proposed by many studies (e.g., Moser, Stevens, and Watts (1989), Neuhäuser (2002), Ruxton (2006), or Zimmerman (2004)).

\subsection{Downsizing decisions}

Table 1 summarizes the absolute and relative frequency of firms that lay off the less productive worker after the first two rounds. Downsizing occurs in all three treatments, but significantly less than all firms downsize (binomial tests for all three treatments: $p<.001$ ).

In treatment $\mathrm{AH}, 72.9 \%$ of firms (35 of 48 firms) fire their less productive workers and even $78.1 \%$ in the AL-treatment (25 of 32 firms), although in AH theoretical gains from downsizing are with $33.3 \%$ larger than in AL with 7.7\%. Factual gains are also higher in AH than in AL (see Section 5.4 below). The differences in downsizing frequencies between treatments are, however, insignificant, according to Fisher's Exact test $(\mathrm{p}=.793$, Note 19). In conclusion, hypothesis I predicting that the size of theoretical gains are relevant for the frequency of downsizing is not confirmed.

Result 1: There are only negligible differences in downsizing frequencies between all three treatments.

\subsection{Treatment $A H$}

Table 2 gives the decisions and payoffs for $\mathrm{AH}(48)$ before and after the downsizing decision, distinguishing between a) all 48 observations (abbreviated and indexed all, if inevitable), b) firms that did downsize (firms $D$, 35 obs.), and c) firms that did not downsize (firms $N D, 13$ obs.). If observations are missing, e.g., for the effort $e_{l}$ of a fired worker, table cells are left empty. We do not index the treatment when it is obvious.

As expected, fixed wage offers are slightly larger than the minimum wage of 24 before and after downsizing 
(ranging from 24.81 to 25.79 ), but do not differ greatly between periods or subgroups. Piece-rate offers, on the other hand, are much smaller than their benchmark level of $r=12$. This is very surprising, since calculators were in heavy use (Note 20). The average piece rate offered over all firms before downsizing is only $r_{B}=8.42$ and remains at about the same low level, $r_{A}=8.06$. Firms D, on average, offer lower piece rates before downsizing, $r_{B, D}=7.73$, than firms ND, $r_{B, N D}=10.27$. After downsizing, firms D offer $r_{A, D}=7.46$, firms ND $r_{A, N D}=9.67$. Due to the much larger variance among firms $\mathrm{D}$ (std. dev.: 4.38 and 1.98), these differences are slightly insignificant on the 5\%-level when performing Mann-Whitney U-tests and robust rank-order tests (Before downsizing: U-tests (rro tests): $p=.087$ (.060), after downsizing: $p=.063$ (.052), Note 21). In summary, hypothesis II is partly confirmed, and partly rejected.

Result 2.AH: Offered fixed wages slightly exceed the benchmark predictions. Piece-rate offers are below optimum throughout.

Due to the low piece rates, comparing efforts to their benchmark levels is futile. Thus, Table 3 presents data for relative deviations, i.e., the quotient between the absolute deviations (the difference between chosen and optimal effort level) and the optimal effort, named reldev (Note 22). Values larger (smaller) than zero indicate efforts above (below) the level predicted for payoff-maximizing agents.

According to Tables 2 and 3 highly productive workers' deviations are only slightly above 0 . We do not observe a sharp decrease in effort levels of highly productive workers who witness layoffs. The moderate decrease of $e_{B, D}=4.06$ to $e_{A, D}=3.79$ is insignificant (dependent sample t test: $p=.273$ ) and mainly due to lower piece-rate offers.

Less productive agents invest more effort than is optimal. Relative deviations lie between .45 and .64 and are all (almost) significantly different from 0 (Note 23). Although contract offers do not change much after downsizing among firms $\mathrm{ND}$, the average effort of workers before downsizing, $e_{B, N D}=1.23$, is significantly higher than the average after downsizing, $e_{A, N D}=1.03$ (Wilcoxon paired sample test, $p=.043$, Note 24 ). This confirms the probation period effect predicted in hypothesis III.

Result 3.AH: Highly productive workers behave rather optimally and do not react to witnessing layoffs. Less productive workers tend to spend more effort than optimal, especially during probation periods.

P-participants' average payoffs are lower than the benchmark levels, what is not surprising considering the low piece rates. There is a significant increase of about $30 \%$ in the principals' average payoff from $\mathbb{\Pi}_{\text {B,all }}=23.24$ before downsizing to $\mathbb{\Pi}_{A, \text { all }}=30.09$ (dependent sample $\mathrm{t}$ test: $p=.011$ ), especially for firms $\mathrm{D}$ where the increase from $\Pi_{B, D}=17.72$ to $\Pi_{A, D}=28.90$ is with $63 \%$ even larger (dependent sample $\mathrm{t}$ test: $p<.001$ ). Firms ND, on the other hand, suffer a payoff loss from $\Pi_{B, N D}=38.12$ to $\mathbb{\Pi}_{A, N D}=33.31$ (Wilcoxon paired sample test: $\mathrm{p}=.635$ ) Overall, this emphasizes that not only theoretical, but also factual gains render downsizing profitable. Firms D earned only $\mathbb{\Pi}_{B, D}=17.72$ on average before downsizing while firms ND earned more than twice as much $\left(\mathbb{M}_{B, N D}=38.12\right)$. This difference is significant according to an U-test (rro test) $(p=.001(.002))$ what suggests that principals' profits trigger their downsizing decision. The on average lower profits of downsizing principals may, of course, be due to both, worse contract design and less motivated agents.

Less productive workers, in total, suffer an income loss after downsizing: (averages are $\omega_{B}=27.81$ before and $\omega_{A}=18.65$ after downsizing) whereas in firms ND, earnings do not change much $\left(\omega_{B, N D}=27.19\right.$ and $\omega_{A, N D}=$ 28.47). Overall, hypothesis $I V$ is rejected.

Result 4.AH: Principals' payoffs are lower than predicted and increase after downsizing. Firms ND earn much more before downsizing than firms D, i.e., the P-participants with less motivated agents or worse contract design engage in downsizing.

"Cheap talk"-conjectures of agents' efforts suggest that principals expect higher efforts than optimal. Principals seem to overestimate the less productive workers' efforts comparatively more (relconjl,B$=.57$ ) than those of high productive ones $\left(\right.$ relconj $\left._{l, B}=.87\right)$ with $\left(\right.$ relcon $\left._{j}\right)$ denoting the ratio of actual and conjectured effort. A one sample $\mathrm{t}$ test comparing the difference $\operatorname{conj}_{d}:=$ relconj $_{h, B}-$ relconj $_{l, B}$ with 0 is highly significant $(p<.001)$.

To confirm that downsizing decisions are predominantly influenced by profit, we perform a simple logistic regression. It uses a forward algorithm to check which of all explanatory variables before downsizing influence the binary dependent dummy variable Down taking the value 1 if a firm downsizes and 0 otherwise. This algorithm uses score tests to decide which variable to include next as well as likelihood ratio test to evaluate whether the inclusion improves the model's explanatory power significantly. Formally, our model with $j$ variables can be described by 


$$
\bar{z}_{l}=\ln \left(\frac{p_{l}}{1-p_{l}}\right)=\beta_{0}+\sum_{j} \beta_{i} x_{l}
$$

with $Z_{i}$ as the latent variable and $p_{i}$ determined by the logistic function.

A selection of relevant tables is given in Appendix B. The algorithm stops after step 1, including only the firm's payoff $\mathbb{I}$ as explanatory variable (Note 25). The parameter estimates are $\beta_{0}=3.245$ for the constant and $\beta_{1}=$ -.075 for the coefficient of $\Pi$. Thus, the probability of firing the less productive employee is about $92.4 \%$ when the principal's profit is $\mathbb{\Pi}=10$, about $63.1 \%$ at the theoretical profit before downsizing, $\mathbb{I}=36$, and only about $40.9 \%$ when his profit reaches $\mathbb{\Pi}=48$. Nagelkerke's $R^{2}$ for our regression is $R^{2}=.281$ (Note 26).

Result 5.AH: Firms tend to overestimate effort levels, especially those of less productive workers. Firing decisions are strongly influenced by principals' profits.

\subsection{Treatment $A L$}

In treatment $\mathrm{AL}$, we have 32 observations in total, 25 for firms $\mathrm{D}$ and 7 for firms ND. Table 4 gives an overview of decisions and payoffs.

Fixed wage offers before downsizing are again higher than their benchmark $F=16$, ranging from 18.36 to 18.50 and decline by about 1 ECU after downsizing in all groups. As in treatment AH, piece rate offers are far below the optimum of $r=12$ in all groups. The differences between piece-rates of firms D and ND and before and after downsizing are negligible.

Result 2.AL: Offered fixed wages are above and piece-rates are below their benchmark levels.

Again, H-participants do not react to layoffs of less productive workers. On the contrary, their effort is higher after downsizing, $e_{A, D}=4.40$, than before, $e_{B, D}=4.13$ - probably due to slightly higher piece-rates. L-participants spend only little more effort than optimal and do not indicate a probation period effect. In particular, relative deviations among all firms are reldev $_{l, B}=.26$ and are almost significantly different from 0 (two-sided t test: $p$ $=.058)$.

Result 3.AL: Highly productive workers behave rather optimally and do not react to witnessing layoffs. Less productive workers spend more effort than optimal; there is no probation period effect.

Firms' profits in treatment AL follow a similar pattern to the AH-treatment, i.e., they increase after firing the low productive worker. However, when performing a logistic regression analogous to that of the preceding subsection, the algorithm stops at the null model, not including any explanatory variable at all (see Appendix B for details). Highly productive workers earn less than their benchmark and about the same before and after downsizing.

In treatment $\mathrm{AL}$, firms slightly underestimate the effort choices of highly productive workers $\left(\right.$ relconj $_{h, B}=1.16$ and relconj $\left.j_{l, B}=1.27\right)$, but still overestimate the efforts of less productive workers $\left(\right.$ relconj $\left.j_{l, B}=.75\right)$. Again, a one sample $\mathrm{t}$ test using the difference conjd (average: \% $c_{0 n j} \sim .41$ ) shows that estimation accuracies differ $(p$ $<.001)$.

Result 5.AL: Downsizing firms earn more after layoffs and less than firms ND before downsizing. Firms tend to underestimate effort levels of highly productive workers and overestimate those of less productive workers.

\subsection{Treatments $A H$ and $A L$}

When comparing treatments $\mathrm{AH}$ and $\mathrm{AL}$, we mainly concentrate on aggregate firm level. Since minimum wages differ, we do not compare fixed wages. Piece-rate offers are quite similar before $\left(r_{A H, B}=8.42\right.$ and $r_{A H, B}=8.96$; a two-sided Welch-Satterthwaite $\mathrm{t}$ test (WS test) comparing them is insignificant: $p=.519$ ) and after downsizing $\left(r_{A H, A}=8.06\right.$ and $r_{A L, A}=9.36$, respectively; WS test: $\left.p=.147\right)$.

Let us now try to answer the question why the fraction of downsizing firms in AH is not higher than in AL. The effort levels of less productive workers in firms ND are $e_{l, A H, B}=1.23$ in treatment AH, but only $e_{l, A L, B}=.84$ in AL (U-test (rro test): $p=.015(.010)$ ), although piece-rate offers do not differ much; they are $r_{A H, B}=10.27$ in treatment $\mathrm{AH}$ and $r_{A H, B}=9.43$ in $\mathrm{AL}$ and this difference is insignificant (U-test: $p=.263$ ). This suggests that L-participants in $\mathrm{AH}$, who are not fired later on, spend relatively more effort than those in treatment AL to prevent their firing. This view is supported by the finding that relative deviations among the same worker group are reldev $v_{l, A H, B}=.64$ in $\mathrm{AH}$, but only reldev $v_{l, A L, B}=.10$ in $\mathrm{AL}$, i.e., low productive workers are more motivated in treatment $\mathrm{AH}$. The descriptive finding is confirmed by an U-test (rro test): $p=.037$ (.027). Interestingly, even highly productive workers are more generous in treatment $\mathrm{AH}$ with reldev $v_{h, A H, B}=.11$ than in $\mathrm{AL}$ with reldev $_{l, A H, B}$ $=-.07$ (WS test: $p=.040$ ). It seems as if low productive workers (intuitively) understand their weaker position in 
$\mathrm{AH}$ and manage to appease their principals by rather generous effort choices (Note 27).

Overall, the differences between treatments $\mathrm{AH}$ and $\mathrm{AL}$ suggest that workers are more generous in treatment $\mathrm{AH}$ what might explain that downsizing does not occur more often in treatment AH than in treatment AL.

Result 6: Treatments $A H$ and $A L$ differ in that principals earn more in AL while agents earn less. Before downsizing, especially the less productive workers, who are not fired later on, spend relatively more effort in treatment AH than those in treatment $A L$.

\subsection{Treatment(s) UH (and AH)}

In contrast to treatment $\mathrm{AH}$, participants in $\mathrm{UH}$ are not aware of the downsizing opportunity. We performed UH as a first small check to get an impression whether agents' behavior differs when the firing threat hangs over them like the Sword of Damocles as in treatment AH. Tables 5 and 6 with three firms ND, 13 firms D and 16 firms in total are constructed analogously to the preceding tables.

Fixed wage offers are above optimum, but do not differ before and after downsizing. Piece-rate offers are always far below the optimum. Effort levels are relatively the same across groups of firms and do not differ before and after downsizing. There is no probation period effect $\left(e_{B, N D}=.67, e_{A, N D}=.68\right)$.

Just as in treatment $\mathrm{AH}$, payoffs of all groups are lower than predicted, but the difference is insignificant for less productive employees. The principals' average payoff gain for all firms from before to after downsizing is large but not significant (Wilcoxon paired sample test, $p=.093$ ). H-participants earn almost the same in all groups. Relative conjecture accuracy is similar to treatment AH: Principals overestimate all workers' efforts and conjectures are more accurate for highly productive workers: One sample t test, difference ${ }^{\circ} \mathrm{nj}_{d}$ (average: conj $_{d} \sim .22$ ) against $0, p<.001$.

When comparing treatments $\mathrm{AH}$ and $\mathrm{UH}$, we first checked all contract offers and payoffs and found no significant differences (Note 28). One major difference between $\mathrm{AH}$ and $\mathrm{UH}$ is the rather large, but insignificant difference between effort levels of less productive workers (in firms ND) in treatment $\mathrm{AH}, e_{A H, B}=1.23$, and in treatment UH, $e_{A H, B}=.67$ (U-test (rro test): $p=.179(.203)$ ), partly due to lower piece-rate offers. This, however, cannot account for the large difference between relative deviations among firms ND ( $\operatorname{reldev}_{A H, B}=.64 \mathrm{vs}$. reldev $_{U H, B}=-.29$ ), that is significant, despite the small sample size of firms ND and the conservative two-sided application of the test (U-test (rro test), $p=.041$ (.041)). Apparently, L-participants who anticipate the downsizing decision (treatment $\mathrm{AH}$ ) are more generous than those who cannot foresee being fired (treatment $\mathrm{UH}$ ) - at least among firms that eventually do not fire (Note 29). The probation period effect of treatment AH cannot be found in treatment $\mathrm{UH}$ for which effort levels hardly differ with $e_{A H, B}=.67$ and $e_{A H, A}=.68$. This confirms the respective part of hypothesis III.a:

Result 7: The main trends in treatment UH are largely comparable to those of treatment AH, expect that for firms ND, the L-participants in AH choose higher efforts than those in UH, especially before the downsizing decision.

\section{Conclusion}

We have theoretically and experimentally analyzed downsizing in its natural principal-agent-setting. Surprisingly, it could not be confirmed that its frequency depends on its profitability. However, within a specific treatment the firms downsizing their labor force are those earning less.

We also found that worker participants in the treatment with higher downsizing incentives are investing relatively more effort to pacify their employers and to prevent firing. The empirical fact that downsizing is more often announced than implemented may thus be partly due to employers trying to discipline their employees by such announcements.

Distinguishing between treatments $\mathrm{AH}$ and $\mathrm{UH}$ enabled us to highlight the behavioral effects of anticipating future layoffs. Without such anticipation (as in treatment $\mathrm{UH}$ ), there is no probation period effect. Thus the best managerial practice is to announce the possibility of later downsizing since the probation period effect seems to outweigh the risk for corporate identity feelings. Overall, the workers who were not fired were spending less effort when they did not foresee the downsizing opportunity, i.e., when perceiving one's job as safer one invests lower efforts. For the academic world, for instance, this would advise against tenure jobs.

\section{References}

Andreoni, J., \& Miller, J. (2002). Giving according to GARP: an experimental test of the consistency of preferences for altruism, Econometrica, 70 (2), 37-53. doi:10.1111/1468-0262.00302, http://dx.doi.org/10.1111/1468-0262.00302 
Berninghaus, S.K., Güth, W., Hoppe, C., \& Paul, C. (2007). International competition in hiring labour and selling output: A theoretical and experimental analysis. In W. Franz, H.J. Ramser \& M. Stadler (Eds.). Dynamik internationaler Märkte. Schriftenreihe des Wirtschaftswissenschaftlichen Seminars Ottobeuren, vol. 36 (pp. 221-246) Tübingen: Mohr Siebeck.

Berninghaus, S.K., Güth, W., Hoppe, C., \& Paul, C. (2009). Duopolistic hiring and sales competition: A theoretical and experimental analysis. Working Paper.

Bolton, G.E., \& Ockenfels, A. (2000). ERC: A theory of equity, reciprocity, and competition. American Economic Review, 90(1), 166-193. doi:10.1257/aer.90.1.166, http://dx.doi.org/10.1257/aer.90.1.166

Brandts, J., \& Charness, G. (2004). Do labour market conditions affect gift exchange? Some experimental evidence. The Economic Journal, 114, 684-708. doi:10.1111/j.1468-0297.2004.00237.x, http://dx.doi.org/10.1111/j.1468-0297.2004.00237.x

Charness, G., \& Rabin, M. (2002). Understanding social preferences with simple tests. Quarterly Journal of Economics, $\quad$ 117(3), 817-869. doi:10.1162/003355302760193904, http://dx.doi.org/10.1162/003355302760193904

Cox., J.C. (2004). How to identify trust and reciprocity. Games and Economic Behavior, 46, 260-281. doi:10.1016/S0899-8256(03)00119-2, http://dx.doi.org/10.1016/S0899-8256(03)00119-2

Davis, D.D., \& Holt, C.A. (1993). Experimental Economics. Princeton: Princeton University Press.

Dufwenberg, M., \& Kirchsteiger, G. (2004). A theory of sequential reciprocity. Games and Economic Behavior, 47, 268-298. doi:10.1016/j.geb.2003.06.003, http://dx.doi.org/10.1016/j.geb.2003.06.003

Falk, A., Huffman, D., \& Macleod, W.B. (2008). Institutions and contract enforcement. IZA Discussion Paper 3435 .

FAZ (2008a). BMW fährt Rekord ein - Aktie stottert hinterher. Frankfurter Allgemeine Zeitung, January, 30, 16.

FAZ (2008b). Nokia: Bochums Ertragskraft wird falsch dargestellt. Frankfurter Allgemeine Zeitung, January, 31, 18.

Fehr, E., \& Fischbacher, U. (2003). The nature of human altruism. Nature, 425, 785-791. doi:10.1038/nature02043, http://dx.doi.org/10.1038/nature02043

Fehr, E., Klein, A., \& Schmidt, K.M. (2007). Fairness and contract design, Econometrica, 75(1), 121-154. doi:10.1111/j.1468-0262.2007.00734.x, http://dx.doi.org/10.1111/j.1468-0262.2007.00734.x

Feltovich, N. (2003). Nonparametric tests of differences in medians: Comparison of the Wilcoxon-Mann-Whitney and robust rank-order tests. Experimental Economics, 6(3), 273-297. doi:10.1023/A:1026273319211, http://dx.doi.org/10.1023/A:1026273319211

Feltovich, N. (2005). Critical values for the robust rank-order test. Communications in Statistics - Simulation and Computation, 34(3), 525-547. doi:10.1081/SAC-200068395, http://dx.doi.org/10.1081/SAC-200068395

Fischbacher, U. (2007). z-Tree: Zurich toolbox for ready-made economic experiments. Experimental Economics, 10(2), 171-178. doi:10.1007/s10683-006-9159-4, http://dx.doi.org/10.1007/s10683-006-9159-4

Fischer, S., Güth, W., \& Köhler, C. (2009). Effects of Profitable Downsizing on Collective Bargaining. In W. Franz, H.J. Ramser, W. Güth \& M. Stadler (Eds.). Schriftenreihe des Wirtschaftswissenschaftlichen Seminars Ottobeuren, vol. 38 (pp. 223-252) Tübingen: Mohr Siebeck.

Fligner, M.A., \& Policello, G.E. (1981). Robust rank procedures for the Behrens-Fisher problem. Journal of the American Statistical Association, 76(373), 162-168. doi:10.2307/2287062, http://dx.doi.org/10.2307/2287062

Frankfurter Rundschau (2008). BMW spart beim Stammpersonal. Frankfurter Rundscha, February, 28, 18.

Greiner, B. (2004). An online recruitment system for economic experiments. In: K. Kremer \& V. Macho (Eds.). Forschung und wissenschaftliches Rechnen, GWDG Bericht, 63. Göttingen: Gesellschaft für Wissenschaftliche Datenverarbeitung.

Handelsblatt (2008). Henkel baut 3000 Stellen ab und BMW greift hart durch. Handelsblat, February, 28, 14-17. Kagel, J.K., \& Roth, A.E. (1995). Handbook of experimental economics. Princeton: Princeton University Press.

Kirstein, A., \& Bleich, S (2008). Screening of endogenous types: an experiment. Working Paper 08-31. 
Moser, B.K., Stevens, G.R., \& Watts, C.L. (1989). The two-sample t test versus Satterthwaite's approximate F test. Communications in Statistics - Theory and Methods, 18(11), 3963-3975. doi:10.1080/03610928908830135, http://dx.doi.org/10.1080/03610928908830135

Neuhäuser, M. (2002). Two-sample tests when variances are unequal. Animal Behavior, 63, 823-825. doi:10.1006/anbe.2002.1993, http://dx.doi.org/10.1006/anbe.2002.1993

New York Times (2008). After a downsizing, how to motivate? New York Times, August, 24. 8.

Rabin, M. (1993). Incorporating fairness into game theory and economics. American Economic Review, 83(5), 1281-1302.

Richter, R., \& Furubotn, E.G. (2003). Neue Institutionenökonomik. 3rd edn. Tübingen: Mohr Siebeck.

Ruxton, G.D. (2006). The unequal variance t-test is an underused alternative to student's t-test and the Mann-Whitney U test. Behavioral Ecology, 17, 688-690. doi:10.1093/beheco/ark016, http://dx.doi.org/10.1093/beheco/ark016

Siegel, S., \& Castellan, N.J. (1988). Nonparametric statistics for the behavioral sciences. $2^{\text {nd }}$ edn. New York: McGrawHill, Inc.

Zimmermann, D.W. (2004). A note on preliminary tests of equality of variances. British Journal of Mathematical and Statistical Psychology, 57, 173-181. doi:10.1348/000711004849222, http://dx.doi.org/10.1348/000711004849222

\section{Notes}

Note 1. Nokia executives stated that these internal numbers are due to accounting regularities and do not represent the factual profitability of the factory at all (see FAZ (2008b)).

Note 2. See, e.g., FAZ (2008a), Handelsblatt (2008) or Frankfurter Rundschau (2008) for detailed information concerning the downsizing announcements, profits, and reactions.

Note 3. Our setting thus fundamentally differs from the ultimatum game environment Fischer et al. (2009) use.

Note 4. We use "agent", "worker" and "employee" synonymously in the remainder and alternate between male and female pronouns for the principal.

Note 5. One can justify co-employment of more and less productive workers by new production techniques which are more easily adopted by some, e.g., the younger workers, but questioning the productivity of others who before were equally skilled. Many other principal-agent models use the same or similar convex functions; see, e.g., Richter and Furubotn (2003).

Note 6. Collective wage agreements or strict anti-discrimination laws justify these assumptions. We do not model labor market competition (see Berninghaus, Güth, Hoppe and Paul $(2007,2009)$ ).

Note 7. To avoid further complexity, we refrain from giving agents the option to quit.

Note 8. Non-negativity constraints and second-order conditions are fulfilled.

Note 9. The distances between the boundaries increase with increasing $d$ and vanish for $d \rightarrow k$.

Note 10. Since our predictions did not concern the interaction of announcing downsizing and the size of incentives and thus can be tested by these three treatments, the fourth one with unannounced downsizing and low incentives has been neglected.

Note 11. Here, our study also fundamentally differs from Fischer et al. (2009), where social welfare is maximized with downsizing.

Note 12. Principals were restricted to fixed wage offers $F$ with $24 \leq F \leq 40$ in treatments AH and UH, and $16 \leq F$ $\leq 40$ in AL. For piece-rate offers we demanded $0 \leq r \leq 20$, for efforts $0 \leq e \leq 10$. One decimal point was allowed.

Note 13. Other experimental studies also use techniques to avoid financial suicide of participants (see, e.g., Falk, Huffman, and MacLeod (2008)).

Note 14. See Davis and Holt (1993) or Kagel and Roth (1995) for comprehensive discussions of dictator and public good experiments and, e.g., Andreoni and Miller (2002), Charness and Rabin (2002), or Fehr and Fischbacher (2003) on human altruism and social preferences.

Note 15. Checking this procedure via two sample Mann-Whitney U-tests for the most important variables, we found only one significant difference for low productive workers' efforts in $\operatorname{AL}(p=.043)$. All other tests yielded much higher $p$-values, data on request. 
Note 16. They differed only in a few words in one line. For participants in AH they stated: "again, you will receive your participation fee" $F F$. For participants in UH they stated: "again, you will receive both your participation fees (45 ECU each)" $F F_{1}+F F_{2}=F F$.

Note 17. Mann-Whitney U-tests: 32 and 16 observations, respectively: $F_{B}(p=.414), r_{B}(p=.265), e_{h, B}(p=.519)$, $e_{l, B}(p=.788), F_{A}(p=.516), r_{A}(p=.028), e_{h, W}(p=.056)$.

Note 18. For the robust rank-order tests, we interpolated the $p$-values delivered by Feltovich (2005) and used the normal distribution as approximation otherwise.

Note 19. Results stay qualitatively the same when using $\mathrm{AH}(32)$ instead of $\mathrm{AH}(48)$. In $\mathrm{AH}(32)$, e.g., $71.9 \%$ of the firms chose to downsize instead of $72.9 \%$ in $\mathrm{AH}(48)$.

Note 20. For example, principal participants in this treatment used the calculator for an average of 95 seconds in each of the $4+4=8$ rounds they played.

Note 21. The only minor difference when using $\mathrm{AH}(32)$ is that the difference in piece rates after downsizing becomes slightly significant.

Note 22. We thereby accept the very few undefined cases in which the piece-rate offer was $r=0$. When only one of the two values that were used to compute averages was missing, we used the other one only.

Note 23. One sample t tests: $p=.009$ for $\operatorname{reldev}_{B, a l l}, p=.051$ for $\operatorname{reldev}_{B, D}$; Wilcoxon paired sample tests: $p<.001$ for reldev $v_{B, N D}, p=.004$ for reldev $_{A, N D}$.

Note 24. This result remains when restricting to $\operatorname{AH}(32)(p=.047)$. Minor changes of $p$-values occur for deviations. Data on request.

Note 25 . We thus need not be concerned about multicollinearity.

Note 26. Results are qualitatively the same for AH(32).

Note 27. The only noteworthy difference when using $\mathrm{AH}(32)$ instead of $\mathrm{AH}(48)$ is that after downsizing piece rates are now significantly larger in AL than in AH (WS test: $p=.032$ ).

Note 28. We omit giving a complete list of tests here. Data on request.

Note 29. Again, all these results stay qualitatively the same for AH(32).For comparison, among firms D the relative deviations do not differ much: reldev $_{A H, B}=.62$ and reldev $_{U H, B}=.75$, (U-test: $p=.790$ ).

\section{Appendix A: Instructions}

Given below are the instructions for the L-employee, treatment AH, partly reformatted to save space. All other instructions are available from the authors on request.

\section{Experiment 1}

\section{General instructions}

Please stop communicating with other participants from now on and turn off your mobile phone. Read the following instructions carefully. If you have a question, please raise your hand, and the supervisors will answer your question at your computer box. We will have to exclude you from the experiment and all payments if you violate these rules. The instructions are identical for all participants except for the subsequent role assignment. Your anonymity will be guaranteed. This means that no other participant is going to learn your identity during or after the experiment.

To begin with, you are taking part in an experiment consisting of 4 periods. After this you will be given new instructions for another experiment!

In the first experiment, three participants will interact. Two of them will take the roles of employees, one will take the role of an employer. One of the employees is of type $\mathrm{H}$ (H-employee), the other of type L (L-employee). There is only one type of employer. The role assignment is carried out randomly in the beginning of the experiment. Each participant keeps his role during the whole experiment. You are an L-employee.

The earnings of every participant depend on his or her own decisions and those of the other participants. Earnings are calculated in ECU (Experimental Currency Unit) during the experiment. At the end of both experiments, they will be converted into Euro at a fixed exchange rate. This exchange rate is $30 \mathrm{ECU}=\mathbf{1}$ Euro.

Additionally, participants receive a fixed participation fee that does not depend on decisions, but will be offset against payoffs if necessary. This participation fee is: $90 \mathrm{ECU}$. 


\section{Periods 1 and 2}

\subsection{General rules}

Each triplet of participants, consisting of an employer, an H-employee, and an L-employee, interacts for 4 periods. Each of the two periods 1 and 2 is basically constructed as follows:

(1) The employer offers one contract that applies to both employees. It consists of two components: a fixed wage $\mathrm{W}$ with $24 \leq \mathrm{W} \leq 40$ and a piece rate $\mathrm{r}$ (with $0 \leq \mathrm{r} \leq 20$ ) that must be paid for each unit of output. Furthermore, the employer has to make conjectures about the employees' effort levels (see 2.). Up to 1 decimal place is allowed for each of the inputs named above.

(2) Knowing the offered contract, each employee independently chooses an effort level, i.e., the H-employee chooses $e_{H}$, the L-employee chooses $e_{L}$. Restrictions are: $0 \leq e_{H} \leq 10$ and $0 \leq e_{L} \leq 10$. Again, up to 1 decimal place is allowed. One unit of effort leads to exactly one unit of output the employer is selling. The gross output $\mathbf{Q}$ thus equals the sum of chosen efforts.

This ends the interactions of a period. Payoffs result as follows:

$$
\begin{gathered}
\text { Employer: }(24-\mathrm{r}) *\left(e_{H}+e_{L}\right)-2 * \mathrm{~W} \\
\text { H-employee: } \mathrm{W}+\mathrm{r} * e_{H}-1 *\left(e_{H}\right)^{2} \\
\text { L-employee: } \mathrm{W}+\mathrm{r} * e_{L}-6 *\left(e_{L}\right)^{2}
\end{gathered}
$$

After each period every participant gets to know effort levels, gross output, and payoffs of all participants.

\subsection{Calculator}

Additionally, the software provides a calculator to each participant. You can use this calculator for two minutes in every period, after which you have to make your decision at the latest. The calculator allows every participant

- $\quad$ to calculate the employer's payoff for various levels of $\mathrm{W}$ and $\mathrm{r}$ and various effort levels $e_{H}$ and $e_{L}$, and

- $\quad$ to calculate the employees' payoffs for various levels of $\mathrm{W}$ and $\mathrm{r}$ and various effort levels $e_{H}$ and $e_{L}$.

Note that as an employer you are only able to make conjectures about effort levels since you do not know the employees' decisions yet. As an employee, however, you know the decisions of the employer. They are preset in the calculator. You will not learn the employer's conjectures.

\subsection{Additional restrictions}

As an additional restriction for the employees, you are limited to choose effort levels - $e_{H}$ or $e_{L}$ - that guarantee that payoffs are larger than or equal to zero in each period. You can check this restriction with the help of the calculator.

As an additional restriction for the employer, you are limited to offers $\mathrm{W}$ and $\mathrm{r}$ that, in addition to the conjectures about effort levels $e_{H}$ and $e_{L}$, also given by yourself, guarantee that expected payoffs are larger than or equal to zero in each period. You can check this restriction with the help of the calculator.

These restrictions imply that period payoffs smaller than zero are only possible for employers, e.g. if effort levels are below conjectured efforts. However, the employer is able to restrict this risk by choosing $\mathrm{W}$ and $\mathrm{r}$ appropriately; payoffs larger zero should be the norm. Payoffs of employers and employees are summed up over the first two periods that are played as described above.

\section{Periods 3 and 4}

Before the third period, each employee may choose between two alternatives:

- $\quad$ keep the L-employee

- $\quad$ lay off the L-employee

The H-employee will always be kept.

If the employer hires the L-employee again (case I), periods 3 and 4 are played analogously to periods 1 and 2 .

If the employer lays off the L-employee (case II), the L-employee will receive a payment of $15 \mathrm{ECU}$ from the experimenters (not from the employer) in each of the periods 3 and 4. Consequently, the L-employee does not make any decisions and does not learn the other participants' payoffs in periods 3 and 4 . In each of the periods of this case (II), the employer offers a new contract to the H-employee only. The same bounds for contracts and effort levels apply. The payoff of the H-employee is calculated as before. Of course, the employer now earns (24 - r) $* e_{H}-$ W. Restrictions are unchanged; calculators are provided again. 
Payoffs of periods 3 and 4 are added to those of periods 1 and 2 and to the participation fee, are converted into Euro, and are paid out anonymously and in cash at the end of both experiments. If the employer's payoff from periods 1 to 4 is smaller than zero, it will be subtracted from the participation fee. If the rest is smaller than zero, it will be offset against the payoffs from the other experiment. If there is still a debt, this has to be paid for at the end of both experiments - either in cash or by administrative work. Please note again as an employer that this situation can be avoided almost completely by choosing $\mathrm{W}$ and $\mathrm{r}$ appropriately; payoffs larger zero should be the norm. The employees' payoffs are always larger than or equal to zero.

In the following last experiment, you will not interact with the same participants as in this experiment again. Before we start the experiment, you have to answer some control questions.

\section{Experiment 2}

We will now repeat the same experiment one more time, i.e., all 4 periods are played again. This means that again, you will receive your participation fee and additional payments, depending on your decisions. Payoffs of all periods are added, converted, and paid out as before. Furthermore, you keep the same role as in the previous experiment, but it is guaranteed that no one will be matched with the same participants again.

Please stay silently at your seat at the end of the experiment until we call you individually and anonymously with the help of your box number and pay you off.

\section{Appendix B: Logistic regression results, treatments AH and AL}

Tables 7, 8, and 9 give the relevant output tables for the logistic regression of the dependent dummy variable Down defined in subsection 5.2 for treatments AH and AL. Due to the few undefined values of reldev $_{h}$, the final regression for treatment AH was performed for only 46 of 48 values. The results differ negligibly when using all 48 observations or only П1. We used a forward algorithm to check whether to include any of the 17 explanatory variables we observed before downsizing. These variables were the fixed wage, the piece rate, efforts, payoffs, absolute and relative effort deviations as well as effort conjectures, and their absolute and relative deviations from optimum effort. The algorithm uses score tests to decide which variable to include next as well as likelihood ratio test to evaluate whether the inclusion improves the model's explanatory power significantly. The algorithm stops after step 1, including only the firm's payoff $\mathbb{I}$ as explanatory variable. The result of the likelihood ratio omnibus test for this first step compared to the null model without explanatory variables tells us that the inclusion of $\mathbb{I}$ contributes significantly $(p=.002)$. For step 0 of treatment $\mathrm{AH}$, where predictions suggest that downsizing took place, 33 out of 46 observations are predicted correctly, a ratio of $71.7 \%$. After step 1 , the model predicts $78.3 \%$ of observations correctly; these classification tables are not depicted.

Table 1. All treatments, downsizing decisions

\begin{tabular}{|c|c|c|c|c|}
\hline \multirow{2}{*}{ Treatment } & \multicolumn{2}{|c|}{ Downsizing } & \multicolumn{2}{c|}{ No downsizing } \\
\cline { 2 - 5 } & Abs. freq. & Rel. freq. & Abs. freq. & Rel. freq. \\
\hline $\mathrm{AH}$ & 35 & $72.9 \%$ & 13 & $27.1 \%$ \\
\hline $\mathrm{AL}$ & 25 & $78.1 \%$ & 7 & $21.9 \%$ \\
\hline $\mathrm{UH}$ & 13 & $81.2 \%$ & 3 & $18.8 \%$ \\
\hline
\end{tabular}

Table 2. Treatment AH, main results

\begin{tabular}{|c|lr|lr|lr|}
\hline & \multicolumn{2}{|c|}{ a) All } & \multicolumn{2}{c|}{ b) Only firms D } & \multicolumn{2}{c|}{ c) Only firms ND } \\
& Before & After & Before & After & Before & After \\
\hline $\mathrm{F}$ & 25.22 & 25.64 & 25.37 & 25.79 & 24.81 & 25.23 \\
\hline$r$ & 8.42 & 8.06 & 7.73 & 7.46 & 10.27 & 9.67 \\
\hline$e_{h}$ & 4.40 & 4.17 & 4.06 & 3.79 & 5.32 & 5.19 \\
\hline$e_{l}$ & & .92 & & .81 & 1.23 & 1.03 \\
\hline $\boldsymbol{I}$ & 23.24 & 30.09 & 17.72 & 28.90 & 38.12 & 33.31 \\
\hline$\omega_{h}$ & 46.04 & 45.45 & 44.28 & 43.84 & 50.79 & 49.77 \\
\hline$\omega_{l}$ & 27.81 & 18.65 & 28.04 & 15.00 & 27.19 & 28.47 \\
\hline
\end{tabular}


Table 3. Treatment AH, effort deviations

\begin{tabular}{|l|lc|cc|cc|}
\hline & \multicolumn{2}{|c|}{ a) All } & \multicolumn{2}{c|}{ b) Only firms D } & \multicolumn{2}{c|}{ c) Only firms ND } \\
& Before & After & Before & After & Before & After \\
\hline reldev $_{h}$ & .11 & .04 & .13 & .02 & .08 & .08 \\
\hline reldev $_{l}$ & & .62 & & .62 & .64 & .45 \\
\hline
\end{tabular}

Table 4. Treatment AL, main results

\begin{tabular}{|c|lr|lr|lr|}
\hline & \multicolumn{2}{|c|}{ a) All } & \multicolumn{2}{c|}{ b) Only firms D } & \multicolumn{2}{c|}{ c) Only firms ND } \\
& Before & After & Before & After & Before & After \\
\hline $\mathrm{F}$ & 18.47 & 17.45 & 18.50 & 17.57 & 18.36 & 17.00 \\
\hline$r$ & 8.96 & 9.36 & 8.83 & 9.61 & 9.43 & 8.46 \\
\hline$e_{h}$ & 4.26 & 4.34 & 4.13 & 4.40 & 4.74 & 4.14 \\
\hline$e_{l}$ & & .87 & & .88 & .84 & .80 \\
\hline $\mathbb{I}$ & 32.82 & 36.56 & 30.20 & 36.38 & 42.16 & 37.21 \\
\hline$\omega_{h}$ & 40.03 & 42.35 & 39.62 & 43.83 & 41.52 & 37.07 \\
\hline$\omega_{l}$ & 21.66 & 16.05 & 21.52 & 15.00 & 22.20 & 19.81 \\
\hline
\end{tabular}

Table 5. Treatment UH, main results

\begin{tabular}{|c|cr|lr|lr|}
\hline & \multicolumn{2}{|c|}{ a) All } & \multicolumn{2}{c|}{ b) Only firms D } & \multicolumn{2}{c|}{ c) Only firms ND } \\
& \multicolumn{1}{|c|}{ Before } & After & Before & After & Before & \multicolumn{1}{c|}{ After } \\
\hline $\mathrm{F}$ & 26.52 & 25.71 & 26.79 & 25.95 & 25.33 & 24.67 \\
\hline$r$ & 7.98 & 8.93 & 7.98 & 9.11 & 8.00 & 8.17 \\
\hline$e_{h}$ & 4.46 & 4.48 & 4.37 & 4.47 & 4.83 & 4.50 \\
\hline$e_{l}$ & & .79 & & .82 & .67 & .68 \\
\hline$\Pi$ & 22.65 & 33.31 & 23.14 & 35.02 & 20.53 & 25.88 \\
\hline$\omega_{n}$ & 44.74 & 48.13 & 44.28 & 49.24 & 46.75 & 43.33 \\
\hline$\omega_{l}$ & 28.97 & 17.34 & 28.95 & 15.00 & 29.05 & 27.47 \\
\hline
\end{tabular}

Table 6. Treatment UH, effort deviations

\begin{tabular}{|l|lc|lc|lc|}
\hline & \multicolumn{2}{|c|}{ a) All } & \multicolumn{2}{c|}{ b) Only firms D } & \multicolumn{2}{c|}{ c) Only firms ND } \\
& Before & After & Before & After & Before & After \\
\hline reldev $_{h}$ & .15 & .00 & .08 & -.02 & .46 & .08 \\
\hline reldev $_{l}$ & & .55 & & .75 & -.29 & -.19 \\
\hline
\end{tabular}


Table 7. Treatment AH, logistic regression: other variables (Variables not in the equation)

\begin{tabular}{|c|c|c|c|c|}
\hline Step 1 & Variables & Value & df & Sig. \\
\hline & $F$ & .277 & 1 & .599 \\
\hline & $r$ & .076 & 1 & .783 \\
\hline & conj $_{h}$ & .000 & 1 & .992 \\
\hline & conj $_{l}$ & .071 & 1 & .790 \\
\hline & $e_{h}$ & .476 & 1 & .490 \\
\hline & $e_{l}$ & .396 & 1 & .529 \\
\hline & $\omega_{h}$ & .027 & 1 & .870 \\
\hline & $\omega_{l}$ & .435 & 1 & .510 \\
\hline & absdev $_{h}$ & 2.769 & 1 & .096 \\
\hline & absdev $_{l}$ & .355 & 1 & .551 \\
\hline & absconj $_{h}$ & .672 & 1 & .412 \\
\hline & absconj $_{l}$ & .006 & 1 & .938 \\
\hline & reldev $_{h}$ & .549 & 1 & .459 \\
\hline & reldev $_{l}$ & .326 & 1 & .568 \\
\hline & relconj $_{h}$ & .019 & 1 & .889 \\
\hline & relconj $_{l}$ & .003 & 1 & .955 \\
\hline
\end{tabular}

Table 8. Treatment AH, logistic regression: relevant variables (Variables in the equation)

\begin{tabular}{|r|lccccc|}
\hline Step 1 & B & S.E. & Wald & df & Sig. & $\operatorname{Exp~(B)~}$ \\
\hline$\Pi$ & -.075 & .032 & 5.666 & 1 & .017 & .928 \\
\hline Constant & 3.245 & 1.150 & 7.957 & 1 & .005 & 25.663 \\
\hline
\end{tabular}

Table 9. Treatment AL, logistic regression (Variables not in the equation)

\begin{tabular}{|c|c|c|c|c|}
\hline Step 0 & Variables & Value & df & Sig. \\
\hline & $F$ & .010 & 1 & .919 \\
\hline & $r$ & .167 & 1 & .683 \\
\hline & conj $_{h}$ & 2.760 & 1 & .097 \\
\hline & conj $_{l}$ & .974 & 1 & .324 \\
\hline & $e_{h}$ & .615 & 1 & .433 \\
\hline & $e_{l}$ & .060 & 1 & .806 \\
\hline & $\mathbb{I}$ & 1.706 & 1 & .192 \\
\hline & $\omega_{h}$ & .101 & 1 & .751 \\
\hline & $\omega_{l}$ & .170 & 1 & .680 \\
\hline & absdev $_{h}$ & .681 & 1 & .409 \\
\hline & absdev $_{l}$ & .257 & 1 & .612 \\
\hline & absconj $_{h}$ & 1.408 & 1 & .235 \\
\hline & absconj $_{l}$ & .761 & 1 & .383 \\
\hline & reldev $_{h}$ & 1.449 & 1 & .229 \\
\hline & reldev $_{l}$ & .441 & 1 & .507 \\
\hline & relconj $_{h}$ & 2.906 & 1 & .088 \\
\hline & relconj $_{l}$ & .171 & 1 & .680 \\
\hline
\end{tabular}

